\title{
Peroxisome Proliferator-Activated Receptor Gamma Coactivator 1-Alpha
}

National Cancer Institute

\section{Source}

National Cancer Institute. Peroxisome Proliferator-Activated Receptor Gamma

Coactivator 1-Alpha. NCI Thesaurus. Code C116295.

Peroxisome proliferator-activated receptor gamma coactivator 1-alpha (798 aa, 91

$\mathrm{kDa}$ ) is encoded by the human PPARGC1A gene. This protein plays a role in the regulation of gene transcription. 